\title{
Alberto Acosta, expresidente de la Asamblea Nacional Constituyente de Ecuador, sobre algunas lecciones del proceso constituyente ecuatoriano
}

\author{
Claudia Iriarte Rivas (iD \\ Universidad de Chile
}

\section{Introducción}

Luego del triunfo de la opción que aprueba la elaboración de una nueva constitución para el país y del mecanismo de convención constitucional, se avecinan grandes desafíos y oportunidades para Chile. En específico, la de escribir una Carta Fundamental nacida en democracia y ampliamente participativa.

Esto exige un compromiso de toda la ciudadanía para plasmar en ella los anhelos de un país que se manifestó desde octubre de 2019 por mayor igualdad, acceso a derechos económicos y sociales y, en definitiva, por la dignidad.

En esta oportunidad conversamos con Alberto Acosta, expresidente de la Asamblea Nacional Constituyente de Ecuador, sobre la experiencia ecuatoriana en la elaboración de una nueva constitución y algunas lecciones que puedan guiar el proceso constituyente chileno ya en marcha.

¿Cómo fue el proceso para llegar a una asamblea constituyente? ¿Cuáles fueron las principales dificultades que enfrentaron?

La Asamblea Constituyente en Ecuador, que se instaló al finalizar el año 2007, fue resultado de un complejo proceso de luchas y de construcción de alternativas que se inició años antes.

Cabe tener presente que, a diferencia de la historia constitucional chilena, Ecuador es un país con adicción a las constituciones y también a las asambleas constituyentes y constitucionales. Así, desde la existencia de Ecuador como república independiente en el año 1830, este país registra, a la fecha, 21 constituciones, lo que no 
puede ser visto como un logro.

Es preocupante esta inestabilidad, que nos permite encontrar hoy la existencia de fuerzas políticas en esencia conservadoras - liberales y «socialistas», incluyendo los correistas- que plantean cambiar la Constitución del 2008, que fuera la primera constitución aprobada en forma mayoritaria en un referéndum luego de una asamblea constituyente.

La Constitución anterior, del año 1998, no contenía una disposición que permitiera abrir la puerta a una asamblea constituyente, por lo que llegado el momento hubo que disputar esa posibilidad y cristalizarla afectando dicho marco constitucional a través de un referéndum.

El pueblo en las urnas autorizó la convocatoria a dicha asamblea, estableciendo algunos elementos relativos sobre cómo debía ser la elección de asambleístas y su duración. Dispuso inclusive la realización del mencionado referéndum luego de aprobada la nueva constitución en la Asamblea Constituyente.

Así, a partir de una masiva decisión popular, el 15 de abril del 2007, con más del $80 \%$ de respaldo, se abrió paso a la Asamblea Constituyente. Las elecciones de asambleístas se celebraron el 30 de septiembre del mismo año, incluyendo algunos mecanismos que aseguraban la participación equitativa de las mujeres en la conformación de las listas y sistemas de financiamiento estatal igualitario para todas las candidaturas.

Tanto la instalación como el desenvolvimiento de la asamblea se dio en el marco de un proceso permanente de discusión pública y de participación ciudadana, tanto en el seno de la Asamblea como en el resto del país. La sociedad movilizada fue en esencia la verdadera asamblea constituyente.

Por esa razón, a contrapelo de los otros procesos constituyentes ecuatorianos, encerrados casi siempre en marcos institucionales conservadores y controlados por las élites, el proceso de los años 2007-2008 fue abierto, con una enorme participación popular, sobre todo en sus primeros siete - de los ocho- meses de duración.

Para lograr esta gran participación, entre otras medidas, se organizaron alrededor del trabajo de la Asamblea diez mesas constituyentes. Esto facilitó el procesamiento de los temas y permitió llevar el debate a todas las provincias y a una gran cantidad de cantones del país. Producto de esa gran participación ciudadana, sin desconocer varios problemas metodológicos y logísticos, se pudo recoger y sistematizar los cientos de propuestas constitucionales, desde simples artículos hasta constituciones enteras. Finalmente, el 28 de setiembre del 2008 , con más del $80 \%$ de los votos válidos, el pueblo aprobó la Constitución elaborada por la Asamblea Constituyente de plenos 
poderes.

¿La normativa que regulaba la convocatoria al proceso constituyente establecía límites al trabajo de la asamblea? De ser así, ¿cuáles eran? ¿Cómo se fijó su reglamentación de funcionamiento interno y qué establecía a grandes rasgos?

Salvo las normas aprobadas en el referéndum de abril del 2007 para definir cómo se convocaba la elección de asambleístas y el plazo de duración de máximo ocho meses, así como la ratificación o rechazo popular de la nueva Constitución, el resto de los temas para normar su funcionamiento los resolvió la propia Asamblea Constituyente.

En Ecuador, después de haber vivido una confrontación traumática entre el Congreso Nacional y la Asamblea Constitucional en el año 1998; de ver los permanentes conflictos que se vivían en ese entonces en Bolivia por la permanencia en paralelo de la Constituyente y del Poder Legislativo; y de aprender de la experiencia colombiana de 1991, en la que se licenció al Congreso, se resolvió cesar al Congreso mientras durase la Asamblea Constituyente.

Sin embargo, quedó abierta la puerta para que el Congreso retomara sus funciones si el pueblo no aprobaba en las urnas la nueva Constitución. En el interim, la misma constituyente asumió todas las funciones legislativas.

De la larga experiencia constitucional ecuatoriana, sabíamos que si se quiere evitar frustraciones, es preciso que el poder constituyente - representante directo del pueblo- subordine al poder constituido, sobre todo al Ejecutivo y al Legislativo.

Una constituyente genuina no puede prosperar atrapada por las normas impuestas por el poder constituido, como parece sucedería en Chile con la Ley 21.200.

Cabe anotar que la constituyente en Ecuador procesó las renuncias de todas las autoridades del Poder Ejecutivo y de control, ratificando en su cargo a unas, como al mismo presidente Rafael Correa, y nombrando directamente otras.

Para el funcionamiento exitoso de la Asamblea fue fundamental contar desde el inicio con un instructivo de instalación. Al inicio de las sesiones, sin dilaciones, como sucedió en Bolivia, se expidió un reglamento interno libre de todas las trabas que puedan poner estorbos al poder constituyente. Así, entre otros temas básicos, se resolvió que se aprobarían los textos de la nueva constitución con una mayoría de 50\% más uno, para evitar el veto de los grupos de poder que sabíamos pretenderían proteger sus privilegios. Cabe señalar que lo anterior se hizo a pesar de tener en el Movimiento Alianza País (movimiento oficialista) una gran mayoría de asambleístas: 70 de los 130; mayoría que luego superó las 100 personas con las alianzas que se fueron forjando en el proceso de construcción democrática de la 
nueva carta magna.

En lo referente al contenido mismo de la Constitución, en cuanto a avances y profundización democrática, ¿cuáles son los aspectos sustanciales que destacaría del texto constitucional que se elaboró?

Toda constitución refleja un momento histórico, cristaliza procesos sociales acumulados y plasma una determinada forma de entender la vida. No es el mero resultado de un ejercicio jurídico de avanzada, como lo ven algunos entendidos en materia constitucional. Tampoco resulta del esfuerzo de varios individuos iluminados. Una constitución, más allá de su indudable trascendencia jurídica, es siempre un proyecto político. Así, la Constitución de Montecristi (ciudad en la costa, alejada de los grandes centros urbanos, en donde se cristalizó la Constituyente) propone un proyecto político de vida en común, con elementos que avizoran inclusive un cambio civilizatorio, como es el tema de los derechos de la naturaleza.

En esta Constitución - dentro de lo que se entiende como el neoconstitucionalismo trasformador - se reconocieron las demandas y expectativas acumuladas en la sociedad ecuatoriana, sintonizándose incluso con problemas regionales y globales.

Desde esa aproximación, hay que asumir a la Constitución no como una simple meta que refleja los objetivos de las luchas de resistencia y de construcción de nuevas visiones de vida, pues en realidad es un punto de partida para construir, en democracia, otro tipo de sociedad eminentemente democrática. Una constitución transformadora, como la de Montecristi, no es un instrumento para mantener el statu quo. Su contenido recoge múltiples alternativas y propuestas de transformaciones de fondo, planteadas al calor de décadas de resistencias y de luchas sociales que tanto dolor le costaron al pueblo ecuatoriano.

La Constitución, en síntesis, se fraguó a través de una suerte de minga democrática inédita en la compleja historia constitucional del Ecuador. Más que la labor misma de los y las asambleístas, fue crucial el concurso de muchas organizaciones sociales que apoyaron y propiciaron un debate democrático y plural alentado desde Montecristi, enfrentando posiciones conservadoras y retardatorias hasta desde el propio presidente Rafael Correa y su Gobierno. De tales luchas, resistencias, debates y propuestas surgieron varias profundamente innovadoras, aunque no exentas de tensiones y contradicciones, de las que mencionaremos un par.

El buen vivir, que surge desde el seno de las tradicionalmente marginadas culturas de los pueblos originarios, y que en kichwa se conoce como sumak kawsay, plantea una «alternativa al desarrollo». Esto confronta con la tradicional visión de desarrollo. Sin negar la tensión no resuelta en el texto constitucional, bien podemos rescatar la significación de varios planteamientos constitucionales que permiten avizorar al buen vivir como una opción posdesarrollista por construir. 
Otro punto clave es el de los derechos de la naturaleza. Por primera vez en una constitución a nivel mundial se acepta a la naturaleza como sujeto de derechos. Esta aproximación difiere de los derechos ambientales propios de los derechos humanos, en tanto cuestiona la civilización antropocéntrica. En el texto aprobado surgen, sin embargo, varias tensiones. Destaquemos, por ejemplo, la dimensión de sujeto de derechos confrontada con la visión de la naturaleza como mera proveedora de recursos y cuya propiedad corresponde al Estado.

La Constitución, con sus 444 artículos, rompió, además, la visión clásica que prioriza unos derechos sobre otros, al reconocer su interdependencia. Esta Constitución clasifica a los derechos de forma distinta a la tradicional y colonizadora aproximación eurocéntrica. Todos los derechos tienen igual jerarquía, pero siempre aceptando la necesidad de garantizar la vida digna y de proteger a grupos de atención prioritaria: mujeres, niñez, discapacitados, así como a comunidades, pueblos y nacionalidades, incluyendo a la naturaleza. A su vez, todos estos derechos tienen un correlato en una sección dedicada a las responsabilidades; es el caso de la propiedad, que en cualquiera de sus formas debe asumir siempre su responsabilidad social y ambiental.

Entre otros temas fundamentales, se puso en entredicho al caduco Estado nación, al declararlo plurinacional e intercultural. Esta cuestión, sin embargo, no pasa de una simple declaración, pues hasta el momento no ha habido ningún avance digno de resaltar.

Dichas conquistas constitucionales, que intentaron sintetizar los anhelos populares, obviamente son difíciles o imposibles de aceptar - e incluso de entender-para los constitucionalistas tradicionales y para los conservadores de todo cuño. Por eso quienes ven amenazados sus privilegios con la Constitución de Montecristi, o se asumen como los únicos portadores de la verdad acotada a la modernidad, no descansan en combatirla. Así, en estos años han convergido diversas posiciones conservadoras desde múltiples ideologías — de liberales a «socialistas»— opuestas a elementos esenciales de la Constitución.

Aún falta hacer un balance crítico sobre la situación actual y el impacto de la Constitución en la sociedad ecuatoriana. Lo cierto es que, desde su aprobación, ésta ha sufrido y sufre reiteradas violaciones. Ejemplos claros son la «metida de mano a la justicia» en mayo de 2011 impulsada por Correa, vía una consulta inconstitucional; los también inconstitucionales cambios a la Constitución en diciembre de 2015, retirados luego en 2018 a través de la misma Corte Constitucional que aceptó los cambios de 2015 y que casi nunca estuvo a la altura del espíritu de Montecristi; y la gran cantidad de leyes y disposiciones atentatorias a la Constitución, empezando por la ley de minería en enero de 2009.

Es evidente que el Gobierno que impulsó la Constitución devino en su mayor transgresor. A Rafael Correa, el caudillo del siglo XXI, la Constitución de Montecristi le resultó una camisa de fuerza para sus apetencias de poder y una camisa de once 
varas ante su incapacidad para cumplir con los cambios profundos propuestos en esa Carta Magna, como pasó con la cuestión de la plurinacionalidad, el buen vivir y los derechos de la naturaleza.

De hecho, hay muchos más temas que merecen analizarse. Entre los que no puede faltar un debate es sobre si la Constitución es el origen del régimen autoritario de Correa. Hay varios puntos cuestionables en la Constitución, incluyendo aquéllos que consolidan tradicionales estructuras y prácticas presidencialistas.

Tampoco se puede centrar la atención sólo en lecturas desde el populismo, buscando explicaciones en la persona del caudillo del siglo XXI. Requerimos lecturas estructurales, como las asociadas a la modalidad de acumulación primario-exportadora: en dicha modalidad de acumulación, de prácticas extractivistas, encontramos las raíces de una economía y un Estado rentísticos, una sociedad clientelar y profundos rasgos de autoritarismo en la gestión del Gobierno. ¡A más extractivismo, menos democracia! Es evidente.

Eso deja claro que una Constitución garantista no asegura en la práctica que las instituciones y el Gobierno sean consecuentes con los postulados constitucionales, ni tampoco que la Constitución sea la herramienta clave para engendrar al autoritarismo. La realidad no se escribe con una constitución. Las personas no gozan de los derechos constitucionales sólo por estar consagrados en el texto constitucional, ni tampoco ganan poderes especiales por el mero hecho de que éstos se encuentren escritos en el papel. La vigencia de la Constitución es un aspecto que debe disputarse desde la lucha política concreta.

Si bien una constitución no cambia la realidad, su conocimiento y vigencia contribuyen a modelarla. Por eso, para que su cumplimiento genere confianza, cohesión social e institucionalidad, se precisa una sociedad en marcha, empoderada de su constitución, que participe en su elaboración, que haga realidad el cumplimiento de sus derechos y garantías y que cumpla con sus obligaciones. También, como parte de ese empoderamiento, se necesita que la misma sociedad cuestione a la Constitución $\mathrm{y}$ vea todo aquello que necesite mejorarse y superarse.

En concreto, la sociedad debe disputar la vigencia y perfeccionamiento permanente de su Constitución. Eso, a pesar de las dificultades enunciadas en párrafos anteriores, es lo que ha sucedido en varios campos. En la disputa de los derechos de las mujeres, la Constitución permitió impulsar procesos muy interesantes y potentes para enfrentar la violencia de género e inclusive para desarrollar políticas y medidas que permitan mejorar los niveles de información y control de la natalidad, aunque sin ser suficientes para alcanzar las metas trabajadas arduamente por lo movimientos feministas. Aquí pesaron las posiciones conservadores del presidente Correa, que terminaría por desmontar los avances logrados entregando el control de la natalidad a personas vinculadas al Opus Dei. En la creciente resistencia a los extractivismos 
(minero y petrolero, en particular) paulatinamente se han ido consolidando los derechos del buen vivir y de la naturaleza, como se refleja en un creciente número de sentencias favorables al respecto.

En síntesis, la Constitución establece bases para desarrollar leyes, políticas y acciones a construirse desde las experiencias de cada persona y grupo implicado. Es la sociedad la que escribe la Constitución, y es la sociedad la que tiene que apropiarse de la Constitución como una herramienta de transformación.

En materia de derechos y sus garantías, ¿qué destacaría de la propuesta constitucional elaborada?

Una constitución construida en clave democratizadora demanda reforzar el sistema de garantías de los derechos, pues los catálogos de derechos sin los correspondientes y eficaces mecanismos de protección quedan en simples declaraciones. Varios son los puntos que se pueden anotar. Aquí apenas una selección de cuestiones trascendentes señaladas con algunas críticas que, a la luz de lo sucedido desde entonces, asoman como relevantes incluso para el proceso constituyente en marcha en Chile.

En línea con la fuerza motivadora de un proceso constituyente genuino, que se podría sintetizar en la ampliación del derecho a tener derechos, en Montecristi ampliaron los ya existentes, incluyendo inclusive nuevos, como son los derechos de la naturaleza, mientras de forma simultánea se reforzó el sistema de garantías de los derechos.

Los catálogos de derechos sin las correspondientes y eficaces garantías quedan en simples declaraciones, simples listados enunciativos. Un punto importante radica en la acción de protección (amparo o tutela) de derechos como una de las principales garantías jurisdiccionales, que no debe tener ninguna restricción o condicionalidad para su ejercicio, como aquélla de que antes de accionarla debe agotarse la vía administrativa o las acciones judiciales ordinarias legales ante la justicia común.

Por igual se diseñaron los mecanismos y las garantías para rodear de total independencia y autonomía a la función judicial, que es lo último que le queda al ciudadano y a la ciudadana frente al despotismo, autoritarismo o arbitrariedad del poder político; la justicia debe controlar toda la actividad del Estado, y los jueces y las juezas deben ser custodios de los derechos, de la legalidad y de la constitucionalidad. Una tarea que quedó trunca por actuaciones del presidente Rafael Correa, quien a través de un plebiscito, el 7 de mayo del 2011, consultó sobre esta norma, sin lograr su aprobación.

En este mismo sentido, es fundamental reforzar los sistemas de control constitucionales con una efectiva e impoluta corte constitucional; su autonomía es clave. Eso demanda rodear de salvaguardas al accionar de la corte y sus integrantes. La esencia 
del Estado de derecho es la capacidad de controlar en todo momento el imperio de la constitución. Aquí también los avances fueron limitados por la intromisión abusiva del Ejecutivo.

Uno de los puntos fuertes tiene que ver con la participación ciudadana. La lista de aspectos en este campo es larga; por ejemplo, todo lo que se refiere a las diversas consultas establecidas en la constitución. Destaquemos la consulta prelegislativa para todas aquellas cuestiones que puedan afectar a los pueblos originarios; la consulta previa, libre e informada debe estar acompañada siempre del consentimiento libre e informado en todos los temas que considere vital una comunidad indígena; la consulta ambiental para los grupos no indígenas; o la consulta popular sobre «temas de interés» que puede ser accionada, cumpliendo una serie de requisitos, por parte de la propia ciudadanía y de los gobiernos autónomos descentralizados. Hay avances en este campo, pero todavía insuficientes.

Discutir el sistema político y la estructura del Estado es otra tarea muy importante. No basta con declarar un Estado intercultural y plurinacional. La tarea es construirlo. En este punto, como se anotó antes, el déficit es total. Por igual, no se lograron establecer las bases para construir verdaderos partidos políticos en vez de maquinarias electorales. Este es un tema vital, que va de la mano con la mencionada participación ciudadana, con el fin de crear verdaderas y efectivas instancias de democracia participativa y control social.

Aspectos también cruciales son los que nos remiten a la organización misma de la economía. El ser humano, con sus derechos vitales, debe ser el centro de toda la actividad económica. Los derechos a una vida digna que asegure educación y salud gratuitas, tanto como vivienda y trabajo como derechos fundamentales, están en el corazón de la Constitución. Esto nos condujo a un tema crucial anotado antes: desmontar la pirámide de derechos tan tradicional en nuestras constituciones, que pone a un nivel equivalente al derecho a la propiedad con los otros derechos que aseguran la vida; la propiedad debe cumplir siempre una función social y ecológica, sin que pueda llegar a transformarse en un factor de disolución de las relaciones económicas y sociales, por ejemplo, a través de estructuras y prácticas oligopólicas. Temas como impedir el acaparamiento de la tierra y del agua también fueron considerados, pero no pudieron ser finalmente contemplados.

Un punto resaltado a nivel mundial es la aprobación constitucional de la naturaleza como sujeto de derechos. Una cuestión que aparece con creciente urgencia mirando los graves retos que enfrenta la humanidad en medio del colapso climático en marcha; colapso que, en Chile, país altamente vulnerable, se registra a través de la crisis hídrica, la desertificación, los incendios forestales, el aumento del nivel del mar, los aluviones en el norte, entre otras manifestaciones. De lo anterior se desprenden muchas acciones en el ámbito constituyente, por ejemplo, la necesidad de impedir, 
desde la vigencia de los derechos de la naturaleza, la mercantilización del agua y de los servicios ambientales como un primer paso para hacer realidad de manera plena dichos derechos, para crear las condiciones para que el ser humano viva en armonía con la naturaleza. Resolver el tema de los bienes comunes será un asunto de vital trascendencia.

Nos planteamos también romper con el binarismo entre más Estado o más mercado. En ningún caso una constitución emancipadora puede ahondar las instituciones y tendencias mercantilizadoras existentes; a los mercados, heterogéneos y plurales como son, hay que ubicarlos en su verdadera dimensión y asegurar los mecanismos adecuadas para que no existan oligopolios o tendencias que ahonden esas estructuras. Estructuras Estadocéntricas tampoco caben en una sociedad que busca su emancipación. El Estado cumple un papel importante, pero eso no significa alentar la vigencia de un Estado rentista y patrimonialista, menos aún centralizador a ultranza. Es imprescindible, entonces, que se creen las condiciones necesarias para asegurar un creciente agenciamiento social. Sobre todo desde los niveles comunitarios, habrá que replantearse en forma radical el Estado y los mercados.

Es más que evidente, una constitución tiene que consolidar la soberanía en plural, permitiendo que se haga realidad la soberanía alimentaria, la soberanía energética y la soberanía económica, que hoy se ve tan amenazada por marcos supranacionales que se muestran como de libre comercio y de protección de inversiones. Las soberanías en plural deben partir de la soberanía del cuerpo, en sintonía con el creciente reclamo femenino y de la diversidad sexual. En la mira debe estar también la construcción de soberanías regionales, sobre las que tendremos que diseñar y llevar a cabo la integración de nuestra América asentada en profundas bases democráticas. Chile, cuyo modelo económico fue presentado como ejemplo del neoliberalismo a nivel regional, ahora podría asumir el liderazgo en la construcción de una integración inspirada en el regionalismo autónomo.

A partir de la experiencia obtenida durante el proceso constituyente, ¿qué consejos u opiniones podría aportarnos para el proceso constituyente que iniciaremos en Chile?

Además de la calidad del debate y del trabajo constituyente en el seno de la Convención o Asamblea, se precisa mucha participación ciudadana y la mayor transparencia posible. Los debates en la Convención y fuera de ella deben ser públicos.

Las visiones contrapuestas, en medio de un proceso democrático, se dilucidan debatiendo con franqueza y asegurando el cumplimiento irrestricto de los derechos humanos en términos amplios, y también de los derechos de la naturaleza. Todo debe ser motivo de un debate profundo, en especial lo relacionado con las condiciones de vida y ciudadanía de las personas. Por ejemplo, si el agua es vida, no puede ser privatizada; la propiedad no puede ser absoluta, debe cumplir en todo momento una 
función social y ambiental; la participación ciudadana no se circunscribe a los procesos electorales, sino que en temas de interés local o popular debe estar asegurada a través de consultas populares; entre muchas otras cuestiones de fondo. Dentro de la vigencia plena de los derechos humanos y de los derechos de la naturaleza, todo; fuera o en contra de ellos, nada.

Al mismo tiempo, la participación no puede detenerse en ningún momento, inclusive luego de concluida la convención constituyente, menos aún si sólo es constitucional. La experiencia chilena demuestra que se llegó a este histórico momento en que se puede cambiar una constitución impuesta por una sangrienta dictadura por la movilización de la sociedad. Presiones para bloquear el proceso constituyente van a estar presentes de manera permanente. Los grupos de poder no van a ceder fácilmente sus privilegios. Los intentos por bloquear un proceso constituyente genuino son múltiples, empezando por la mencionada Ley 21.200, o como los que surgen de lecturas que consideran la dictadura pinochetista apenas como una «interrupción» en los «más de 160 años de vida democrática» de Chile, al decir de Tomás Pablo Roa, presidente ejecutivo de Wolf y Pablo Consultores, empresa que recoge en sus regulares informes las preocupaciones de los grandes grupos económicos ante los avances de democratización de la sociedad chilena.

Por eso, es preciso que el debate constituyente se enraíce en la sociedad chilena para que sus ciudadanas y sus ciudadanos asuman de manera efectiva el papel de asambleístas constituyentes a través de todos los espacios de debate posibles y, por cierto, desde la constante presión que se puede y debe ejercer desde las calles. La participación hay que conjugarla en todo momento, sobre todo sin pedir permiso.

Contando esos dos pilares mencionados (participación ciudadana y transparencia), es obvio que el debate en el seno de la Asamblea resulta fundamental. Para que prospere este proceso de complejas pero indispensables transformaciones, hay que aceptar que los temas a tratar son todos. No hay límites, salvo los que puedan impedir la vigencia plena de los derechos humanos y los derechos de la naturaleza, que en esencia son complementarios y mutuamente potenciadores. La tarea sería impulsar, por un lado, la despatriarcalización y la descolonización de la sociedad, al tiempo que se crean las condiciones para la construcción de una democracia radical en tanto va a la raíz de los problemas. El objetivo de una constitución emancipadora es, entonces, proteger a la sociedad de los potenciales abusos del poder, sean políticos o económicos, que en la práctica caminan juntos.

Teniendo en mente la convergencia de múltiples luchas y reclamos que explican el resultado del referéndum del pasado 25 de octubre, que vienen desde diversas esquinas y desde hace varios años, habría que construir un marco constitucional que entierre la dictadura pinochetista, no sólo cambie su Constitución.

En este momento, además, es preciso extraer las mejores lecciones del momento 
que atraviesa la humanidad, sobre todo las que deja la pandemia del coronavirus, que ha servido como una gran lupa para ver mejor los desequilibrios y desigualdades existentes. Así, para enunciar un par de puntos, es indispensable que la salud sea vista como un derecho, no como un privilegio, es decir, no puede ser una mercancía; la educación debería ser gratuita en todos los niveles; se precisa también abrir la puerta a la soberanía alimentaria pensada desde la producción y el consumo, no sólo desde la lógica de la agroexportación; habría que asegurar una renta básica universal sin condiciones y permanente para erradicar la pobreza extrema; la seguridad social debe ser universal y no un simple mecanismo de acumulación financiera; éstas y otras cuestiones deberían asegurar la vigencia plena de los derechos sociales. Así, teniendo la justicia social en la mira, es indispensable avanzar en paralelo con la justicia ecológica, a partir de los derechos de la naturaleza.

El reto es construir un marco constitucional lo más consensuado posible, a ser alcanzado con una gran participación social, sin que se sacrifiquen los ejes fundamentales para construir una sociedad realmente democrática. El concepto que debe ser conjugado en forma permanente, en clave de participación democrática, es convivencia. Eso solo se consigue si hay libertad, igualdad, equidad, justicia...

En la región, Ecuador ha sido pionero en la formulación de alternativas al sistema hegemónico de solución de controversias en materia de comercio e inversiones internacionales. ¿Hubo una discusión en la Asamblea Constituyente sobre la tensión entre la protección de los derechos humanos y los compromisos de comercio e inversiones internacionales? ¿Desde el punto de vista de los derechos humanos, cómo evalúa el impacto de la cláusula de reserva de soberanía jurisdiccional frente a instancias de arbitraje internacional en materia de comercio e inversión?

Para empezar, ubiquemos en el texto de la Constitución el tema. Allí se prohíbe celebrar tratados o instrumentos internacionales en los que el Estado ecuatoriano ceda jurisdicción soberana a instancias de arbitraje internacional, en controversias contractuales o de índole comercial, entre el Estado y personas naturales o jurídicas privadas. Claramente se exceptúan los tratados e instrumentos internacionales que establezcan la solución de controversias entre Estados y ciudadanos en América Latina a cargo de instancias arbitrales regionales o por órganos jurisdiccionales de designación de los países signatarios. Hay un punto muy interesante en el caso de controversias relacionadas con la deuda externa, que prevé que el Estado ecuatoriano aliente soluciones arbitrales en función del origen de la deuda y con sujeción a los principios de transparencia, equidad y justicia internacional.

Para entender el objetivo de esta disposición, recordemos que los tratados bilaterales de inversión surgieron de un intento fallido por establecer una suerte de constitución económica global que proteja los derechos de los inversionistas internacio- 
nales. Este Acuerdo Multilateral de Inversiones (AMI) se discutió - a espaldas de la mayoría de los Estados del planeta- en la segunda mitad de los años noventa del siglo pasado.

En pleno auge neoliberal, en el marco de la Organización para la Cooperación y el Desarrollo Económico (OCDE), se pretendió hacer realidad este marco jurídico supranacional con alcance global. Si se hubiera aprobado el Acuerdo Multilateral de Inversiones, habría establecido claros límites a los ámbitos del ejercicio de la democracia, así como a los derechos laborales, a las políticas sociales, a la misma pluralidad cultural planetaria, incluyendo la relación con la naturaleza. Huelga decir que no pudo ser aprobado por la resistencia de amplios segmentos sociales en varios países de la propia OCDE, que entendieron con claridad los riesgos que esto implicaba.

A partir de esta realidad, las grandes corporaciones transnacionales y los Gobiernos más poderosos comenzaron a idear e instrumentar otros mecanismos de protección supranacional para los inversionistas extranjeros por vías bilaterales. Recordemos que los mecanismos instalados antes, que recurrían incluso al uso de la fuerza, estaban proscritos por la creciente vigencia de la doctrina Calvo.

La experiencia de Ecuador con estos tratados es larga, compleja y muy onerosa. La lista de demandas planteadas y de sentencias que afectan los intereses nacionales lo demuestra. Basta revisar el informe final de la Comisión para la Auditoría Integral Ciudadana de los Tratados de Protección Recíproca de Inversiones y del Sistema de Arbitraje Internacional en Materia de Inversiones (CAITISA), creada en el Gobierno de Correa - que no dio paso a la vigencia inmediata de la Constitución en este tema-. Cabría tan sólo traer a colación los sonados arbitrajes en el caso ChevronTexaco, el caso Oxy, los casos Perenco y Burlington; como hecho reciente, recordemos el chantaje de las transnacionales mineras, las que, a pesar de hacer actividades que afectan la Constitución y las leyes, es decir, la esencia de la seguridad jurídica, amenazan con demandar usando este mecanismo si se permite el cumplimiento de un derecho constitucional: las consultas populares sobre la minería, por ejemplo. La lista de este tipo de arbitrajes comerciales onerosos y hasta vergonzosos, que es lo que a la postre significan estos arbitrajes, es enorme en toda la región.

Como conclusión, estos tratados, que se refieren a relaciones contractuales con múltiples posibilidades, abren las puertas para la cesión de soberanía. Tengamos presente que la legislación de inversión está incorporada en la legislación de comercio; éste es un punto medular para entender cómo las inversiones están íntimamente imbricadas con los temas de comercio. Así, los tratados de inversión forman parte de los tratados de libre comercio.

Conscientes de esta realidad, los y las constituyente de Montecristi, sintonizados con los procesos políticos de inicios del presente siglo, con los que se enfrentaban a los tratados de libre comercio y a los tratados bilaterales de inversión, hermanos siameses del intento para imponer normas globales que cristalicen un sistema de do- 
minación y explotación del capital transnacional, asumieron el reto de elaborar una constitución que garantice como objetivo construir de una sociedad democrática. Por esa razón, no se podía permitir que se protegieran los derechos de las inversiones extranjeras sobre los derechos de los seres humanos y de la naturaleza, lo que pondría en riesgo hasta políticas sociales y de otra índole, creando inclusive una situación que privilegie a dichos inversionistas en perjuicio de los empresarios nacionales.

Afirmar que con estos tratados se asegura un mejor ambiente de negocios y de condiciones de inversión, es decir, un mejor ambiente comercial, es incompleto. Hacen falta muchos más factores: entre otras cosas, se deben crear las condiciones para un desenvolvimiento dinámico de la economía imbricada en una sociedad que tenga bases sólidas de equidad.

La prioridad en Ecuador, vista desde la Constitución de Montecristi, la tienen o la deberían tener las inversiones nacionales. En consecuencia, mal se haría en establecer un esquema que otorgue una posición privilegiada a las inversiones extranjeras, a las que se libera de los requisitos de desempeño, de procesos de expropiación directa o indirecta (en los marcos que establece la Constitución); de toda restricción al movimiento y repatriación de capitales; inclusive de la aplicación de políticas sociales, laborales o ambientales que podrían afectar sus ganancias. Además, de esta manera la inversión extranjera, complementaria de la nacional, como manda la Constitución, podría dejar de respetar de manera estricta el marco jurídico nacional, empezando por la Carta Magna. Esto sería inaudito.

La seguridad jurídica debe ser para todos, es decir, para la sociedad en su conjunto, para las comunidades, para el Estado y sus empresas, para la ciudadanía y, por cierto, para la naturaleza, no sólo para el capital privado. Esta seguridad jurídica múltiple - cuya vigencia demanda integralidad, como se establece en la Constitución- debe darse a partir de la premisa de que en este país el eje es el ser humano viviendo en armonía con la naturaleza, lógica que debe normar los acuerdos y convenios internacionales.

De hecho, la Corte Constitucional terminó por aceptar la inconstitucionalidad de 17 tratados de este tipo. La mencionada CAITISA, creada el año 2013 y que cerró sus actividades en el año 2017, concluyó que estos tratados firmados por Ecuador no fueron determinantes en la atracción de la inversión extranjera directa. Ecuador tenía más tratados que muchos países de la región y, sin embargo, recibía sólo 0,79\% de dicha inversión que llegaba del mundo a América Latina y el Caribe. El principal flujo de inversiones extranjeras directas hacia Ecuador provenía de Brasil, México y Panamá, países con los que Ecuador nunca firmó un tratado bilateral de inversiones. Dicho esto, se ve que la existencia de los tratados no fue ni el detonante, menos aún el argumento fundamental, para llevar a cabo esas actividades de tipo comercial en el Ecuador. Como si lo anterior no fuera un argumento suficiente, téngase presente 
que -comparando dos países de la región de tamaño relativamente similar- Brasil, sin tratados bilaterales de inversión, supera en inversiones extranjeras a México, uno de los países con más tratados de inversión.

En síntesis, cabe tener presente la integralidad del mandato constituyente. Los tratados bilaterales de inversión y los llamados tratados de libre comercio no deberían afectar puntos clave de la Constitución aprobada en el año 2008, como son el tema de las soberanías en plural: soberanía económica, soberanía alimentaria, soberanía energética; aquellas disposiciones que garantizan la vigencia plena de los derechos humanos, incluyendo el agua como un derecho fundamental, de los derechos de la naturaleza, entre otros puntos.

Estas disposiciones constitucionales fueron atropelladas con la firma del TLC con la Unión Europea a fines del año 2016, por parte del gobernante que juraba que nunca firmaría un TLC y que afirmaba solemnemente, en el año 2008, que la nueva Constitución duraría «30o años».

La inconsecuencia gubernamental con la Constitución de Montecristi se conjuga también con el lamentable desperdicio de la década "progresista». En lo político, se debió dar paso a una democracia radical, más horizontal y participativa en todos los ámbitos, pero se hizo todo lo contrario: no hubo ni revolución ni ciudadanía, como rezaba la propaganda, se terminó por construir nuevamente un caudillismo puro y duro. En términos económicos, no hubo cambios en la matriz productiva, se ahondaron los extractivismos abriendo la puerta a la megaminería, ampliando la frontera petrolera, consolidando los monocultivos. Si bien en un inicio se redujo la pobreza, no se modificaron para nada las lógicas que reproducen la desigualdad y la concentración de la riqueza, con lo que a la postre, durante el auge petrolero y aún más después, los principales beneficiarios fueron los grandes grupos económicos. A pesar de que el «progresismo» ecuatoriano - como sucedió con los otros Gobiernos «progresistas»- se llenó la boca con discursos revolucionarios y socialistas, apenas se intentó modernizar el capitalismo, lo que dio paso, en paralelo, a la profundización de la dependencia del mercado mundial en tanto país suministrador de materias primas. Triste saldo de una década que empezó con muchas ilusiones y expectativas de cambio.

\section{Sobre la autora}

Claudia Iriarte Rivas es abogada. Doctora en Derecho, investigadora del Centro de Derechos Humanos de la Facultad de Derecho. Actualmente se desempeña como editora del Anuario de Derechos Humanos. Su correo electrónico es ciriarter@derecho.uchile.cl. (D) https://orcid.org/00oo-0003-0449-926X. 
El Anuario de Derechos Humanos es una publicación semestral de referencia y consulta en materia de derechos humanos y campos afines. Busca ser un espacio de discusión de los temas centrales en el ámbito nacional e internacional sobre derechos humanos. Es publicado desde 2005 por el Centro de Derechos Humanos de la Facultad de Derecho de la Universidad de Chile.

\author{
EDITORA \\ Claudia Iriarte Rivas \\ ciriarter@derecho.uchile.cl \\ SITIO WEB \\ anuariocdh.uchile.cl \\ CORREO ELECTRÓNICO \\ anuario-cdh@derecho.uchile.cl \\ LICENCIA DE ESTE ARTÍCULO \\ Creative Commons Atribución Compartir Igual 4.o Internacional
}

\author{
\% \\ La edición de textos, el diseño editorial \\ y la conversión a formatos electrónicos de este artículo \\ estuvieron a cargo de Tipográfica \\ (www.tipografica.io)
}

